\title{
In Praise of Human Dignity: The Humanities in the Age of Big Data
}

\author{
Hava Tirosh-Samuelson (Arizona State University)
}

Introduction: The Crisis of the Humanities

The humanities have lost their prestige, funding, identity, and public purpose (Arum \& Roska, 2001; Kronman, 2007; Ferrall, 2011; Delbanco, 2012). Many metrics attest to crisis on undergraduate and graduate levels in the United States: low enrollments in humanities courses; decline in the number of majors; fewer degrees earned; the loss of positions; fewer graduate training programs; lower numbers of tenure-track jobs advertised and poor academic job markets (Hayot, 2018). The factors that contributed to the decline of the humanities include cuts in funding for education on state and federal levels; increased tuitions that leave many students with heavy debt that takes years to repay; the reluctance of parents to invest in humanities education because they do not secure a path to employment; competition with STEM education on diminishing public resources, and the economic ethos and corporate models that pervade institutions of higher learning. If previously degrees in the humanities have assured decent income, employment, and entry into the middle class, today these social goods are no longer guaranteed. The humanities are no longer perceived as a path to success in North-American society (Bérubé, 2013).

Structural changes in North-American society have undoubtedly contributed to the crisis of the humanities, but the root causes for the decline of the humanities go much deeper. I argue that a key factor is the postmodernist critique of the philosophical assumptions which have undergirded the modern worldview. The two World Wars in the 20th century exposed the dark side of Enlightenment rationality and its concomitant ideology of "progress" by means of science and technology. While modernity witnessed the improvement of the standard of living for millions of people, the horrors of Auschwitz and Hiroshima made clear that modernity did not make human life more safe, just, or peaceful. Rather, technoscience was used to exterminate people who were deemed to be "sub-human," manufacture death on an industrial scale, and threaten the very viability of life on Earth. The Enlightenment grew out of Renaissance humanism, which had celebrated the dignity, distinction, and excellence of humanity, but by the mid-20th century "humanism," the ideology of freedom and progress, have proved to be most problematic. In the post-War years "philosophical/critical posthumanism" and "technoscientific transhumanism" were articulated to critique and replace "humanism," although like all other 'posts,' 'posthumanism' also perpetuated some humanist assumptions, especially the claim that humans are alone responsible for their own destiny. Those who advocated and theorised the 'posthuman condition' have directly contributed to the crisis of the humanities we now experience and lament.

\section{Posthumanism and Transhumanism}

The term 'posthumanism' was first used in the Macy Conferences on cybernetics from 1946-1953 with the invention of system theory that searched for

“... a new theoretical model for biological, mechanical and communicational processes that removed the human and Homo sapiens from any particular privileged position in relation to matters of meaning, information and cognition" (Wolfe, 2010, xii).

Cybernetics, "the scientific study of control and communication in the animal and the machine," (Wiener, 1948) came into existence after World War II, but since then the term has been applied to the scientific study of how humans, animals, and machines control and communicate with each other. Cybernetics deliberately erased the boundaries between human and the non-human, between man-made artifacts and organic systems, between social behaviour and natural life. Cybernetics thus characterised the posthuman condition as the breakdown of traditional dichotomies (e.g., nature/culture; men/women; human/animal), the hybridisation and fusion of elements that were previously kept apart, and the decentering of humanity from its previous position of privilege as the "zenith of creation" (Ps. 8:3-4a; 5 NRSV). In educational terms, cybernetics inspired the interdisciplinary study of various fields including mechanical engineering, evolutionary biology, neuroscience, anthropology and psychology, bringing about the integration of the natural sciences, social sciences, communication, engineering, and business, resulting in marginalization of the humanities (Pickering, 2010).

The emergence of "posthumanism" as a new theoretical framework went hand in hand with the rise of postmodernism as a wholesale critique of modernity. 
Postmodernist philosophers (e.g., Jacques Derrida, Michel Foucault, Jean-Francois Lyotard, and Jean Baudrillard) proclaimed the "End of Man", by which they signified the demise of humanism, namely, a conception of humanity which has prevailed in the West since the Renaissance. As Robert Pepperell put it, the posthuman condition signifies the end of "the long held belief in the infallibility of human power and the arrogant belief in our superiority and uniqueness" (Pepperell, 2003, p. 100). The "End of Man" thus signified the critique of philosophical anthropology and its underlying metaphysical assumptions and ethical ramifications, which postmodernist philosophers claimed to be unjust, repressive, and exploitative. Although the postmodernist critique intended to liberate humanity from unjust, oppressive beliefs and practices, it also undermined the cherished values of Western culture which justified the study of the humanities. If "Man" does not denote universal humanity, what are the humanities about?

Postmodernism and the counter-culture revolutions of the 1960s brought about profound transformation of higher education as new perspectives, including feminist, environmentalist, queer, ethnic, and post-colonial, critically engaged the humanistic canon from their own distinctive vantage point, dismantling any claim for universality (Hollinger, 2006). While expanding the scope and diversifying the content of the humanities, they also signalled the emergence of "posthumanism" as a replacement of the humanistic paideia whose roots go back beyond the Renaissance to antiquity (Spanos, 1993). Cultural posthumanists have insisted that humanism is not only a harmful dogma, but also that humanism is replete with its own prejudices which are precisely the kind of "superstition" from which the Enlightenment called us to break free. Cultural posthumanists uncovered the repressive implications of humanism for women, minorities, occupied and oppressed social groups and even animals. Since all boundaries are socially constructed, so the argument went, the marginalization and repression of any group is inherently unjust and must end. Similarly the artificial boundaries between "humans" and "non-humans" had to collapse, whether the "nonhumans" are animals, machines, aliens, or monsters (Graham, 2002).

The collapse of boundaries between nature and culture, the organic and the inorganic, humans and animals would generate a new understanding of human embodiment. It was expressed most powerfully by the figure of the Cyborg, a term coined already in 1960 by Manfred E. Clynes and Nathan S. Kline to denote a "cybernetic organism," namely a being with organic and bio-metronic body parts (Clynes \& Klein, 1960). In 1985 Donna Haraway articulated the liberationist potential of cyborgisation in her Cyborg Manifesto, a feminist project that sought to reconstitute a new identity politics about gender norms (Haraway, 1985; Haraway, 1990). Thereafter, the Cyborg figure was used to represent the complex relationship between humanity and technology, develop narratives that explore the imaginative possibilities inspired by new technologies, or theorise the relationship between humans and machines (Haraway \& Hables-Gray, 1995). The Cyborg discourse entered many cultural forms such as films, science fiction, performance and installation art and horror genre, and in all of these cultural modalities the human body was defamiliarized, depicted so as to inspire revulsion, or disengaged from its biological nature as the body is dissolved into electronic space and cybernetics existence. The "End of Man" meant not only the demise of theoretical assumptions about universal reason and human rights, but also the demise of the biological basis of human existence, the human body (Halberstam \& Livingston, 1995; Hayles, 1999).

By the end of the 20th century, however, the fusion of humans and machines was no longer idle phantasy of cultural posthumanists who interpreted literary texts or visual images, but a technological possibility brought about by the convergence of genetic engineering, robotics, informatics, nanotechnology, and applied cognitive science. This convergence and the advances in the life sciences, neuroscience, and medicine has been marshalled to facilitate the enhancement of human physical and mental characteristic, elimination of disease and pain, and the radical extension of life expectancy. Techno-optimists (who, ironically enough, endorse the philosophical assumptions of the Enlightenment), hailed the capacity of new technologies to improve the human condition through techno-scientific enhancement that will not only fix a perceived limitations of biological humans but will also facilitate the transition from biological humanity to mechanical posthumanity. The term 'transhumanism,' which was coined by Julian Huxley in 1957 to denote "evolutionary humanism" (Tirosh-Samuelson, 2012, p. 56-64), emerged as the ideology that advocates the necessary, indeed inevitable, transition from biological humanity to mechanical posthumanity in which the human species will be superseded by decision-making, super-intelligent machines (More and Vita-More, 2013). Put differently, transhumanism is the programme that will bring about techno-scientific posthumanism, the desired telos. But make no mistake: the goal of techno-scientific posthumanism is not the "End of Man" as a philosophical concept or the "End of Education" as a program for selfcultivation, but rather the end of humanity as a biological species.

In the transhumanist futuristic narrative, the end of biological humanity will come about gradually: at first there will be the Mechanical Age in which humans create robots that serve human needs (hence they are called "servers"), culminating with the uploading of human consciousness unto super-intelligent machines that will supersede the intellectual abilities of their human makers. Eventually the robots "will tire caring for humanity and will decide to spread throughout the universe in the interest of discovering all the secret of the cosmos" 
(Geraci 2008, p. 151). At that point, the Age of Robots will be supplanted by the Age of Mind, where machines will create space for "subtler world" in which computations alone remain. In the Virtual Kingdom, the "Mind Fire" will render earthly life meaningless, ultimately swallowed by cyberspace (Moravec, 1988; Moravec, 1999). This futuristic vision presents itself in secular, technoscientific terms, but in truth it is a secularisation of age-old religious motifs: the human quest for transcendence (Tirosh-Samuelson, 2017). Whether or not the technological transcendence is scientifically feasible is still hotly debated, but there is no doubt that transhumanist futurism has already exerted profound impact on popular culture through films, novels, and video-games (Geraci, 2012; Geraci, 2014). Given the proliferation of trans/posthumanist themes in popular culture, the humanistic outlook and educational practice have been rendered increasingly irrelevant and obsolete. What is the point of humanistic education in age of cybertechnology?

Technology has undoubtedly transformed all aspects of contemporary life as the boundaries between humans and machines have collapsed. We do live now in the socalled Second Machine Age (Brynjolfsson \& McAfee, 2014) as computers, robots, the Internet, and Artificial Intelligence have reconfigured finance, transportation, communication, energy, defence systems, warfare, medicine, labour, leisure, art, culture, education, and human embodiment. The humanities, of course, did not ignore these technological changes nor were they immune to their impact. The major response was the development of the digital humanities (Terras, Nyhan, Vanhoutte, 2012; Warwick, Terras, Nyhan, 2012). In the late 1990s and early 2000 the digital humanities consisted of "large scale digitation projects and the establishment of technological infrastructure" (Berry \& Fagerjord, 2017, p. $35)$. In the second phase since 2010 , the digital humanities created "the environments and tools for producing, curating, and interacting with knowledge that is 'born digital' and lives in various digital contexts" (ibid). Those who promote the digital humanities seek to turn the classroom into "labs" where solutions to concrete problems are proposed through interdisciplinary hands-on learning and they call all humanities scholars to change their research methods by working with Big Data, namely large data sets that can be analysed computationally to reveal patterns, trends, and associations, especially relating to human behaviour and interaction. The computation, digitation, and abstraction that characterise the digital humanities, have transformed many academic practices (Kaplan, 2015; Williamson, 2017) but as scholars of digital humanities now wrestle with the theorising of digital humanities, to inaugurate the third phase of digital humanities, it is time to critically reflect on computational thinking.
The (Analogue) Humanities as Critique of Trans/Posthumanism

We are indeed living in a new moment that calls for new philosophical anthropology, a new holistic framework that could integrate what we now know about the physical world, biological life, and human culture (EsbjornHargens \& Zimmerman, 2009). The new integrative work cannot and will not be carried out by computer scientists and engineers but by intellectuals who can and will reflect on the human values, hopes, aspirations, dreams, and meanings that transcend and even resist computation and calculation. In the age of Big Data, I would submit, the purpose of education is not to turn humans into machines, as trans/posthumanists envision and advocate, but to cultivate the dignity and distinction of biological, nonmechanical humanity. Human distinction does not lie in computation, but in the human capacity to enter a dialogue with the Other through communication and interpretation, in the cultivation of good character traits (i.e., the virtues), and in the capacity to love and to feel empathy toward others especially those who experience pain and suffering. Human beings do live with computers and their interactions with machines will increase over time, but humans are not intelligent machines, contrary to transhumanist claims (Warrick, 2002; O'Connell, 2017). Therefore, human flourishing cannot consists of excellence in computation but instead must take into consideration that human beings are finite biological organisms, that humans are social animals who thrive in polities where justice, equality, and difference are honoured and protected. The humanities are needed today more than ever before to resist the dehumanisation caused by digitation and mechanisation, to transmit cultural heritage to future generations, to prepare the young to assume civic responsibility, to defend democracies against authoritarianism and totalitarianism, and to enable human beings to be compassionate, caring, and loving (Roche, 2010; Nussbaum, 2010). Although humanities research has greatly benefitted from the new technologies, theorising about being human in the age of Big Data should not be left to scholars of digital humanities.

To begin, the humanities remind us that humans should not be reduced to informational "data." Although human behaviour over the centuries can be described by quantifying large data sets, the meaning of being human transcends quantification, computation, and mechanisation. Indeed, the humanities explore aspects of human life that resist quantification: hopes, dreams, aspirations, fantasies, emotions, despair, fear and anxiety. These subjective, mental states do manifest themselves in observable behaviour that can be quantified, but human interiority, personhood, and identity are not quantifiable and cannot be calculated by a machine, no matter how strong its computational power. To truly understand another person requires a personal dialogical encounter which Big Data and automated systems deny us to our 
frustration and dismay. Traditional humanistic education enables human being to engage others in a genuine dialogue, an I-Thou encounter, that is very different from machine-human interface.

A genuine personal dialogue is built on acceptance of the Other and interpretation of subtle intentions, wishes, yearnings, humour, ironies, and self-contradictions which any machine, no matter how "intelligent," is too crude to grasp. The traditional humanities train the student to read texts carefully, to listen to what is being said and how to it is said, to capture the "gaps" and the "silences" of the texts, and to appreciate the particular, unrepeatable individuality of the speaker/author/writer. Such close reading of texts is precisely what traditional biblical hermeneutics was all about. Given our infinite particularity, even if mind uploading will be proven feasible, what will be uploaded will not be us but some simplified version of us that will only resemble us in some way. The study of the humanities enables us to appreciate and celebrate the particularity of human beings, the irreducible richness of individual identity, and the freedom to be different. The humanities teach us how to appreciate and protect human particularity and how to resist the erasure of human distinctiveness by dissolving difference into pattern recognition (Checketts, 2015) is instructive that some of the debates among scholars of digital humanities revolve around how to express the particularity of gender, race, and ethnicity in digitised communication. The study of the humanities enables us to resist generalisations about human beings which only occlude and erase particularity, while at the same time, appreciate what humans have in common with each other, which makes possible communication across cultural, religious, national, ethnic, sexual and gendered divides.

Humans are embodied beings; they are not simply an abstract mind that is imprisoned in a body, as transhumanist anthropology presupposes, but rather beings whose mind and body are holistically interdependent. Transhumanists are particularly disdainful of human embodiment, because it is imperfect, subject to limitations, and above all finite and mortal. Transhumanists are obsessed with fixing the limitations of the human body so as to improve its performance, extend its life indefinitely, and defy its impending death, but humanists who study the human experience in time, appreciate the wisdom of embodiment and mortality and the preciousness of organic life, the very life which transhumanists denigrate and wish to make obsolete. The glory of humanity, then, does not lie in the disembodied consciousness that will be uploaded unto super-intelligent machines where it will engage in perpetual computation, but in the complex mind-body interplay that resists reductionist to either "spiritual" mind or "physical" body. It is the interdependence of mind-body that allows us to sense, perceive, feel, desire, yearn, hope, communicate, and create sophisticated civilisations. The humanities enable us to appreciate human creativity over time, reflect on its diversity and richness, and ensure its perpetuation into the future, even though humans will continue to experience physical and mental disabilities, suffer pain, diseases and illnesses, and be subject to mortality. Embodiment and mortality should not be viewed as human deficiency that should be eliminated by science and technology but rather as the source of much of human glory, since philosophy, religion, and art are all expressions of human awareness of death and the human response to the fact of mortality. By teaching thematic courses that expose students to human reflections on the good life, happiness, friendship, justice, or meaning of life, we can inspire students to reflect about their own life in ways that prepares them to act as mature adults in a world that has become increasingly more complex due to technology.

Encounter of the human experience in all of its complexity, depth, and richness can help students develop critical, self-reflective, interpretative, and communicative skills that are necessary for responsible citizenship in democratic societies. The humanities impart the skills that enable students to differentiate between facts and opinions or between news and fake news, to make cogent arguments and evaluate the evidence in support of conflicting arguments, to question any truth claim and to resist superficial demagoguery. By subjecting texts (printed or digital, verbal or pictorial, auditory or visual) to close analysis, by imaginatively encountering human experiences in other times and places, by interpreting cultures and societies other than our own, students of the humanities learn to function in a democratic society in which citizens must be free, judicious, and responsible. These skills are most needed today when digital communication on social networks such as Facebook and Twitter has flattened communication, vulgarised social interaction, and incited billions of people to act impulsively and even violently. Social networks generate both good and bad social and cultural consequences, but to ensure that their benefits will outweigh their risks, we must teach users of social networks to be more discerning, self-critical, compassionate, tolerant, patient, and selfcontrolled.

In the age of converging technologies, we should not be obsessed about being faster, taller, stronger, smarter, younger-looking, or long living, as transhumanists urge us, but rather being more humane, that is, more caring and less smug, callous, cruel, or indifferent. The care and concern for others is not limited just to other human beings but should extend to the all beings of the natural world, animals, plants, and natural resources, since human well-being is dependent on the well-being of the environment. The character traits that make human beings into caring animals are the same that make human beings less arrogant, exploitative, and destructive to the natural environment. To develop these character traits we need to be connected to our (embodied) emotions, become more attuned to the pain and suffering of others, and more 
attentive of neediness and accepting of vulnerability. All of these skills and attitudes, which transhumanists either dismiss or ignore, cannot be cultivated by means of computation and calculation; they can only emerge by encountering other human beings in real life or through the mediation of texts. Only the humanities can train students to appreciate the complexity of human life with its dialectics of freedom and necessity, individuality and sociality, independence and responsibility, excellence and collaboration. The humanities are essential to addressing the challenges that face humanity today in a technologically saturated world that stands on the brink of extinction given human destructive capacities.

Conclusion:

The humanities study the entire gamut of the human experience. The humanities are as important today as they were in the Renaissance when humanists critiqued the scholastic tradition that had dominated the universities, bringing about an educational reform that eventually gave us the Enlightenment. The humanists who glorified human dignity recovered the ancient past through translations, commentaries, poems, speeches, letters, and historical, grammatical, and rhetorical works that accentuated human free will, human agency, and human choice. The Renaissance humanists challenged the rationalism, naturalism, and determinism of scholastic Aristotelianism and offered a different reflection on the meaning and purpose of human life. We at the beginning of the 21 st century wrestle with the same issues but on a different scale because of human-made technologies that are transforming all aspects of life. Centred on human beings, the humanities encompass the numerous dimensions of being human: individual and social, private and public, emotional and rational, cognitive and behavioural, personal and political, subjective and objective, environmental and technological. Because the humanities always tell the stories of individuals who function as agents of social and cultural change, people who move other people to action because of the power of their ideas, the humanities use narratives that are inherently messy, inexact, dynamic, and open to conflicting interpretations. In the Second Machine Age we must resist the tendency to reduce humans to machines and to equate human dignity with computation. The future of the humanities and of humanity lie not with technoscience and engineering but with humanists who will celebrate the dignity of "being human, all too human."

\section{References}

Arum, R. \& Roksa, J. (2001). Academically adrift: Limited learning on college campuses. Chicago, IL: The University of Chicago Press.

Bérubé, M. (2013). The futility of the humanities. Belfiore, E. \& Upchuck, A (eds.). Humanities in the 21st century: Beyond utility and markets. New York, NY: Palgrave Macmillan, 66-76.

Berry, D. \& Fagerjord, A. (2017). Digital humanities. London: Polity.

Brynjolfsson, E. \& McAfee, A. (2014). The second machine age: Work, progress and prosperity in a time of brilliant technologies. New York, NY: W.W. Norton.

Clynes, M. \& Kline, N. S. (1960). Cyborgs and space. Astronautics, 26-27; 74-76.

Checketts, L. (2015). Recognizing the face and facial recognition. Scalambrino, F. (ed.). Social epistemology and technology:

Toward public self-awareness regarding technological mediation. London: Rowman \& Littlefield, pp. 177-86.

Delbanco, A. (2012). College: What it was, is, and should be. Princeton, NJ: Princeton University Press.

Esbjorn-Hargens, S. \& Zimmerman, Michael E. (2009). Integral ecology: Uniting multiple perspectives on the natural world.

Boston, MA: Integral Books.

Ferrall, V. E. (2011). Liberal arts at the brink. Cambridge, MA: Harvard University Press.

Geraci, R. M. (2008). Apocalyptic AI: Religion and the promise of artificial intelligence. Journal of the American Academy of Religion, 76(1), 138-166.

Geraci, R. M. (2012). Apocalyptic AI: Visions of heaven in robotics, Artificial intelligence and virtual reality. New York, NY: Oxford University Press.

Geraci, R. M. (2014). Virtually sacred: Myth and meaning in the World of Warcraft and Second Life. Oxford: Oxford University Press.

Gold, M. K. \& Klein, L. E. (eds.) (2016). Debates in the digital humanities: 2016. Minneapolis, MN: University of Minnesota Press.

Graham, E. L. (2002). Representation of the post/human: Monsters, aliens and others in popular culture. New Brunswick, NJ: Rutgers University Press.

Halberstam, J. \& Livingston, I. (eds.) (1995). Posthuman bodies. Bloomington, IN: Indiana University Press. 
Hayles, K. N. (1999). How we became posthuman: Cybernetics, literature and informatics. Chicago, IL: Chicago University Press.

Haraway, D. J. (1985). A cyborg manifesto: Science, technology and socialist feminist in the late twentieth century. Socialist Review, 80, 65-80.

Haraway, D. J. (1990). Simians, cyborgs and women: The reinvention of nature. New York, NY: Routledge.

Haraway, D. J. \& Hables-Gray, C. (eds.) (1995). The cyborg handbook. New York, NY: Routledge.

Hayot, E. (2018). The sky is falling. Retrieved from http://mla.hcommons.org/2018/05/21/the-sky-is-falling/

Hollinger, D. (ed.) (2006). The Humanities and the dynamics of inclusion since World War II. Baltimore, MD: Johns Hopkins University Press.

Kaplan, F. (2015). A map for a Big Data research in digital humanities. Frontiers in Digital Humanities, 2(1). http://soi.org.10.3389/fgdigh.2015.00001

Kronman, A. T. (2007). Education's end: Why our colleges and universities have given up on the meaning of life. New Haven, CT: Yale University Press.

Lagemann, E. C. \& Lewis, H. (2011). Renewing the civil mission of american higher education. Lagemann, E. C. \& Lewis, H. (eds.). What is college for? The public purpose of higher education. New York, NY: Columbia University Teachers College Press, pp. 9-45.

Moravec, H. P. (1988). Mind children: The future of robots and human intelligence. Cambridge, MA: Harvard University Press.

Moravec, H. P. (1999). Robots: Mere machines to transcend mind. New York, NY: Oxford University Press.

More, M. \& Vita-More, N. (eds.) (2013). The transhumanist reader: Classical and contemporary essays on the science, technology and philosophy of the human future. Malden, MA: Wiley-Blackwell.

Nussbaum, M. (2010). Not for profit: Why democracy needs the humanities. Princeton, NJ: Princeton University Press.

O'Connell, M. (2017). To be a machine: Adventures among cyborgs, utopians, hackers and the futurists solving the modest problems of death. New York, NY: Anchor Books.

Pepperrell, R. (2003). The posthuman condition: Consciousness beyond the brain. Bristol, UK: Intellect Books.

Pickering, A. (2010). The cybernetics brain: Sketches of another future. Chicago, IL: Chicago University Press.

Roche, M. W. (2010). Why choose the liberal arts. Notre Dame, IN: University of Notre Dame.

Spanos, W. V. (1993). The end of education: Toward poshumanism. Minneapolis, MN: University of Minnesota.

Terras, M., Nyhan, J. \& Vanhoutte, E. (eds.) (2013). Defining digital humanities: A reader. New York, NY: Routledge.

Tirosh-Samuelson, H. (2012). Science and the betterment of humanity: Three british prophets of transhumanism. TiroshSamuelson, H. \& Mossman, K. L. (eds.). Building better humans? Refocusing the debate on transhumanism. Frankfurt am Main: Peter Lang, pp. 55-82.

Tirosh-Samuelson, H. (2017). Technologizing transcendence: A critique of transhumanism. Trothen, T. J. \& Mercer, C. (eds.). Religion and human enhancement: Death, values, and morality. New York, NY: Palgrave Macmillan, pp. $267-84$.

Warwick, C., Terras, M. \& Nyhan, J. (eds.) (2012). Digital humanities in practice. London: Facet Publishing.

Warwick, K. (2002). I, cyborg. Chicago, IL: University of Illinois Press.

Wiener, N. (1948). Cybernetics: Or, control \& communication in the animal and machine. New York, NY: John Wiley and Sons.

Williamson, B. (2017). Big Data in education: The digital future of learning, policy and practice. Los Angeles, CA: Sage. Wolfe, C. (2010). What is posthumanism? Minneapolis, MN: University of Minnesota Press.

\section{Recommended Citation}

Tirosh-Samuelson, H. (2018). In praise of human dignity: The humanities in the age of Big Data. On Education. Journal for Research and Debate, 1(2). https://doi.org/10.17899/on_ed.2018.2.4

\section{About the Author}

Hava Tirosh-Samuelson (Ph.D. 1978, Hebrew University of Jerusalem) is Regents' Professor of History, Director of the Center for Jewish Studies, and Irving and Miriam Lowe Professor of Modern Judaism at Arizona State University in Tempe, AZ. She writes on Jewish intellectual history, religion, science and technology, and religion and ecology. Tirosh-Samuelson is the author of the award-winning Between Worlds: The Life and Thought of Rabbi Judah Messer Leon (1991) and Happiness in Premodern Judaism: Virtue, Knowledge and Well-Being (2003) and over 50 peer-reviewed essays. She is the editor of eight volumes, including Building Better Humans? Refocusing the Debate on Transhumanism (2012) and Perfecting Human Futures: Transhuman Visionsand Technological Imaginations (2016) and the Editor-in-Chief of the Library of Contemporary Jewish Philosophers (2013-2018) a set of 21 volumes. 